\title{
BMJ Open Effect of ethnicity and other sociodemographic factors on attendance at diabetic eye screening: a 12-month retrospective cohort study
}

\author{
Abraham Olvera-Barrios (D , ,,2 Michael Seltene, ${ }^{1}$ Tjebo F C Heeren (D) , ${ }^{1,2}$ \\ Ryan Chambers (D) , ${ }^{3}$ Louis Bolter (D), , Adnan Tufail (D) , , \\ Christopher G Owen (D) ," Alicja R Rudnicka (D) , ${ }^{4}$ Catherine Egan (D) , ${ }^{1,2}$ \\ John Anderson ${ }^{3}{ }^{3}$
}

To cite: Olvera-Barrios A, Seltene M, Heeren TFC, et al. Effect of ethnicity and other sociodemographic factors on attendance at diabetic eye screening: a 12-month retrospective cohort study. BMJ Open 2021;11:e046264. doi:10.1136/ bmjopen-2020-046264

- Prepublication history for this paper is available online. To view these files, please visit the journal online (http://dx.doi. org/10.1136/bmjopen-2020046264).

Received 16 December 2020 Accepted 23 June 2021

Check for updates

(C) Author(s) (or their employer(s)) 2021. Re-use permitted under CC BY. Published by BMJ.

${ }^{1}$ Medical Retina, Moorfields Eye Hospital NHS Foundation Trust, London, UK

${ }^{2}$ University College London Institute of Ophthalmology, London, UK

${ }^{3}$ Homerton University Hospital NHS Foundation Trust, London, UK

${ }^{4}$ Population Health Research Institute, St George's, University London, London, UK

Correspondence to Dr John Anderson; john.anderson@nhs.net

\section{ABSTRACT}

Objectives To examine the association of sociodemographic characteristics with attendance at diabetic eye screening in a large ethnically diverse urban population.

Design Retrospective cohort study.

Setting Screening visits in the North East London Diabetic Eye Screening Programme (NELDESP).

Participants 84449 people with diabetes aged 12 years or older registered in the NELDESP and scheduled for screening between 1 April 2017 and 31 March 2018.

Main outcome measure Attendance at diabetic eye screening appointments.

Results The mean age of people with diabetes was 60 years (SD 14.2 years), 53.4\% were men, $41 \%$ South Asian, 29\% White British and 17\% Black; $83.4 \%$ attended screening. Black people with diabetes had similar levels of attendance compared with White British people. However, South Asian, Chinese and 'Any other Asian' background ethnicities showed greater odds of attendance compared with White British. When compared with their respective reference group, high levels of deprivation, younger age, longer duration of diabetes and worse visual acuity, were all associated with nonattendance. There was a higher likelihood of attendance per quintile improvement in deprivation $(\mathrm{OR}, 1.06 ; 95 \% \mathrm{Cl}, 1.03$ to 1.08 ), with increasing age (OR per decade, $1.17 ; 95 \% \mathrm{Cl}$, 1.15 to 1.19), with better visual acuity (OR per Bailey-Lovie chart line $1.12 ; 95 \% \mathrm{Cl}, 1.11$ to 1.14) and with longer time of NELDESP registration (OR peryear, $1.02 ; 95 \% \mathrm{Cl}, 1.01$ to 1.03).

Conclusion Ethnic differences in diabetic eye screening uptake, though small, are evident. Despite preconceptions, a higher likelihood of screening attendance was observed among Asian ethnic groups when compared with the White ethnic group. Poorer socioeconomic profile was associated with higher likelihood of non-attendance for screening. Further work is needed to understand how to target individuals at risk of non-attendance and reduce inequalities.

\section{INTRODUCTION}

Diabetic retinopathy is a common neurovascular complication of diabetes and a major cause of blindness. ${ }^{12}$ There are at least
Strengths and limitations of this study

- Strengths are that it is the largest population-based study in which the effect of sociodemographic factors on attendance at diabetic eye screening has been examined.

- A large urban multi-ethnic population with a broad range in its indices of deprivation was studied, making the findings widely applicable.

- Data completeness was high in the population.

- A range of additional socioeconomic factors, including the distance to screening centre and public transport accessibility level, were analysed.

- Systemic risk factors for diabetic retinopathy incidence and progression, and the association of sociodemographic variables with diabetic retinopathy were not available to analyse.

3.9 million people diagnosed with diabetes in the UK, a number expected to rise to 5.8 million by $2025 .{ }^{3}$ It is estimated that $30 \%$ of people with diabetes will develop retinopathy, and about 9\% will develop sightthreatening retinopathy. ${ }^{4}$ An early diagnosis through population screening, timely referral and treatment are essential for prevention of diabetes-related visual impairment. ${ }^{56} \quad 7$ The UK implemented the first systematically organised diabetic eye screening programme (DESP) in the world in England in 2003, achieving nationwide coverage by 2008 . The English DESP offers annual mydriatic photographic screening to all people with diabetes aged 12 or older. ${ }^{5}$ In accordance with national standards, screening of $\geq 85 \%$ of the eligible diabetic population is considered achievable, however, English DESP uptake data from 2016 to 2017 showed that this was not met in $75 \%$ of London's Clinical Commissioning Groups (CCGs) areas. ${ }^{89}$ Regional differences 
in screening delivery and uptake may explain regional variation in diabetic eye disease. ${ }^{4}$

Non-attendance at annual diabetic eye screening visits has been associated with late presentation of sightthreatening retinopathy. ${ }^{710}$ Inequalities in health tend to be present in urban areas with contrasting sociodemographic conditions. London, a metropolis where people from the extremes of the deprivation indices live sideby-side, is a remarkable example of how these inequalities can result in different uptake rates across and within boroughs. ${ }^{1-13}$ Health inequalities can create significant attendance variation among subgroups, and are of concern to any screening programme. Sociodemographic factors such as, age, ${ }^{14-21}$ gender, ${ }^{21-23}$ ethnicity, ${ }^{14}{ }^{15} 23$ transportation $^{24}$ and socioeconomic deprivation ${ }^{14-1619-21232526}$ have all been associated with non-attendance.

The North East London population is sociodemographically diverse, with a wide variation in ethnicities and a varied health profile with higher than average levels of deprivation and a lower than average life expectancy. ${ }^{27-29}$ The North East London DESP (NELDESP) serves a total eligible population of approximately 125000 people with diabetes aged 12 and over. ${ }^{27}$ The NELDESP aims to invite $\geq 98 \%$ of eligible individuals and to have an uptake $\geq 85 \%$. We have examined attendance at diabetic eye screening to identify which sociodemographic factors are determinants of attendance in this large multi-ethnic population with high levels of deprivation.

\section{METHODS}

This was a 12-month retrospective cohort study of diabetic eye screening appointments occuring between 1 April 2017 to 31 March 2018. Our outcome measure was attendance at diabetic eye screening. Potential determinants of attendance include age, gender, self-defined ethnicity, area level deprivation, type of diabetes, duration of diabetes, visual acuity, years of NELDESP registration, distance to screening centre, and public transport accessibility.

\section{Setting}

The NELDESP is provided by the Homerton University Hospital NHS Foundation Trust. We analysed data from people with diabetes living in six CCG areas with inner city multi-ethnic populations. These are the London boroughs of Newham, Redbridge, Tower Hamlets and Waltham Forest, classified as the most ethnically diverse in London ${ }^{3031}$; the borough of Hackney and the borough Barking and Dagenham, which both have a substantial multi-ethnic population.

The NELDESP is run according to English DESP guidelines. All people with diabetes aged 12 or older are identified through coding in primary care electronic record systems. Over the course of one year, every person eligible for Routine Digital Screening is offered multiple opportunities to attend. Eligibility for screening is defined by Public Health England. ${ }^{32}$ Software is used to generate invitations to attend for NELDESP appointments. The Homerton Hospital carries out appointment call/recall, screening, image grading, referral tasks, and is responsible for providing clinical leadership and programme management, including failsafe procedures and internal quality assurance. $^{27}$

Briefly, a screening visit entails a visual acuity assessment, and pupil dilation to obtain two $45^{\circ}$ digital retinal images of each eye, centred on the fovea and disc, respectively. We have described in detail the imaging, grading protocol and referral pathway elsewhere. ${ }^{33}$

Any person attending any of the offered appointments over the course of one whole year was defined as 'Attended'. Only those who failed to attend all appointments offered in the period were classified as 'Did not attend'.

\section{Data extraction}

We carried out an anonymised data extraction of all screening appointments within the study period using structure query language (SQL) searches. An anonymised data base for analysis was created.

\section{Independent variable recording \\ Ethnicity}

Self-classified ethnicity data were collected from patients at the time of screening, or from the routinely recorded ethnicity data provided by their general practitioner (GP) surgery. Their ethnicity was recorded in the nationally mandated screening software in accordance with the 2011 Office for National Statistics census groups. ${ }^{30}$

\section{Index of multiple deprivation}

The English indices of deprivation are composed of 39 indicators arranged in seven different domains of deprivation, which are combined and weighted to create the index of multiple deprivation (IMD), the official measure of relative deprivation in England. This measure is calculated for every neighbourhood or small area (lower-layer super output area (LSOA)) in England. There are 32844 LSOAs with an average population of 1500 , and each of them is ranked from $1^{\text {st }}$, the most deprived area, to $32,844^{\text {th }}$, the least deprived area. Patients' postcodes were linked to their LSOA indices of multiple deprivation scores.

\section{Visual acuity, distance and Public Transport Accessibility Level}

We recorded the most recent visual acuity within a 3-year time frame in Snellen notation for the analysis. The better-seeing eye visual acuity score was assigned to each person. We calculated distance to screening centre (in kilometres) as a straight line from the patient's postcode to the screening site. For patients who attended, the postcode used was that known to the NELDESP on the day of attendance. For patients who failed to attend at any point within the study period, the postcode used was that known to the NELDESP on the date of the last offered appointment. The public transport accessibility level (PTAL) is a metric tool from Transport for London which rates locations by distance to the public transport network, thus reflecting the accessibility to public transport within 
Greater London. The PTAL grade takes into account walk access time, average waiting time, service availability and service reliability. The grading has nine levels from 0 (with the poorest access) to $6 \mathrm{~b}$ (excellent access).$^{34}$ Using Transport for London's Web-based Connectivity Assessment Toolkit (WebCAT), ${ }^{35}$ we extracted the PTALs for each patient's home postcode.

\section{Statistical analysis}

We used R V.4.0.0 for statistical analysis. ${ }^{36}$ We conducted a multivariable logistic regression analysis of attendance at screening visit (binary outcome coded ' 1 ' if patient attended and ' 0 ' if they did not attend). A test for linear trend was performed if the ORs showed a linear pattern across categorical variables. Attendance was defined as a participant completing the diabetic retinopathy screening process. Independent variables considered were age, gender, ethnicity, IMD, type of diabetes, duration of diabetes, visual acuity, years of registration into the DESP, distance to screening centre and PTAL.

We categorised continuous variables for the analysis to allow for non-linear patterns in attendance. Rank scores of the IMD were split into quintiles following Office for National Statistics data of the English indices of deprivation 2019, with the $1^{\text {st }}$ quintile being the most deprived and the $5^{\text {th }}$ quintile the least deprived areas. ${ }^{28}$ PTAL was divided into tertiles, with the $1^{\text {st }}$ tertile having the worst PTAL $(0,1 \mathrm{a}, 1 \mathrm{~b})$ and $3^{\text {rd }}$ tertile the best $(5,6 \mathrm{a}, 6 \mathrm{~b})$. Ethnicity was categorised as White British (White British, Irish, Any other White background), Mixed (White and Black Caribbean, White and Black African, White Asian, Any other Mixed background), Black (African, Caribbean, Any other Black background), South Asian (Indian, Pakistani, Bangladeshi), Chinese, Any other Asian background and Any other Ethnic group. Missing data points were categorised as 'Unknown' group within each independent variable.

The reference category for ethnicity was the White British group, for IMD the most deprived quintile, and for PTAL the best tertile. For the rest of the independent variables, the group with the highest number of observations was considered the reference.

\section{Patient and public involvement}

Two patients provided insight into our discussion of the results of this study. We plan to disseminate the findings of our study to people eligible for diabetic eye screening and their families through the local press and via social media. In addition, we intend to seek wider dissemination to the public through the English national screening programme's communication team.

\section{RESULTS}

A total of 84449 people were invited for a screening appointment during the study period. Mean age was 60 years (SD 14.2years), $53.4 \%$ were men and $93.7 \%$ of those invited for screening had type 2 diabetes. The majority were of South Asian ethnicity (41.2\%), followed by White British (29\%) and Black ethnic groups (17\%). $74.7 \%$ of the participants lived in areas with the highest levels of deprivation ( $1^{\text {st }}$ and $2^{\text {nd }}$ IMD quintiles). Overall, screening attendance during the study period was $83.4 \%$.

Table 1 summarises sociodemographic characteristics of attenders and non-attenders along with crude and adjusted ORs for attendance versus non-attendance (where ORs greater than 1 imply greater odds of attendance). In the text we refer to the adjusted OR from the multivariable linear regression model unless otherwise stated.

Those aged 12-45 years of age showed poorer attendance when compared with the reference 46-60 year-old group. In adjusted analyses, participants 18-30 years of age were least likely to attend for screening showing a $58 \%$ reduction in the odds of attendance, and an absolute uptake difference of $18.8 \%$ when compared with the reference. Each decade rise in age increased the odds of attendance by about $17 \%(\mathrm{OR}=1.17$; 95\% CI 1.15-1.19, p-value $<0.001)$.

Compared with White British individuals, those of Mixed or Black ethnicity did not show any difference in the odds of attendance after adjustment. However, odds of attendance were higher among individuals of Asian (South Asian, Chinese and any other Asian background) ethnicities when compared with White British individuals, even after adjustment.

Adjusted analyses showed that individuals living in the least deprived areas (5th IMD quintile) were most likely to attend for their screening appointments. Those in the 5 th IMD quintile showed a $25 \%$ increase in the odds of attendance compared with people living in the most deprived areas (1st IMD quintile). Each IMD quintile increase (i.e. less deprivation) suggested a $6 \%$ rise in the odds of attendance (linear trend test p-value $<0.001$ ).

People with longer duration of diabetes were less likely to attend. The OR per 5-year increase in duration of diabetes was 0.97 (95\% CI 0.95 to 0.99 , $\mathrm{p}$ value $=0.019$ ). The average distance to screening centre was $1.7 \mathrm{~km}$ (IQR $1-2 \mathrm{~km}$ ). Only people who lived $\geq 9 \mathrm{~km}$ from the screening centre (outside the geographical boundaries of the CCGs of North East London) were less likely to attend. Odds of attendance decreased by $1 \%$ for every $\mathrm{km}$ further from the screening centre; a non-signficant trend $(\mathrm{OR}=0.99$; $95 \%$ CI 0.97 to 1 , $\mathrm{p}$ value $=0.031$ )

Individuals with lower visual acuity (starting from visions worse than 6/9) showed a graded decline in the odds of attending the screening visit. Those with visual acuity worse than $6 / 18$ were least likely to attend and showed a $60 \%$ reduction in odds of attendance compared with those with acuity of $6 / 6$ to $6 / 9$. This equates to an absolute difference in attendance of 11 percentage points when compared with the reference group.

Attendance did not appear to differ by gender, type of diabetes or PTAL score. People registered in the screening programme for more than 5 years were more likely to attend than those registered for less than 5 years. 
Table 1 Sociodemographic characteristics of attenders and non-attenders along with crude and adjusted odds ratios (OR) for attendance versus non-attendance

\begin{tabular}{|c|c|c|c|c|}
\hline Dependent: Attended* & Attended $\mathrm{n}=70405(83.4 \%)$ & $\begin{array}{c}\text { Did not attend } n=14044 \\
(16.6 \%)\end{array}$ & $\begin{array}{l}\text { Univariable OR (95\% Cl, } \\
\text { p-value) }\end{array}$ & $\begin{array}{c}\text { Multivariable adjusted OR† } \\
(95 \% \mathrm{Cl}, \mathrm{p} \text {-value })\end{array}$ \\
\hline \multicolumn{5}{|l|}{ Age } \\
\hline $12-17$ years & $276(78.9)$ & $74(21.1)$ & $0.73(0.57-0.95, p=0.016)$ & $0.71(0.52-0.99, p=0.036)$ \\
\hline 18-30years $† \dagger$ & $1003(64.9)$ & $543(35.1)$ & $0.36(0.32-0.40, p<0.001)$ & $0.42(0.36-0.49, \mathrm{p}<0.001)$ \\
\hline $31-45$ years & $8296(77.2)$ & $2454(22.8)$ & $0.66(0.62-0.70, p<0.001)$ & $0.71(0.66-0.76, p<0.001)$ \\
\hline 46-60years (Reference) & $25779(83.7)$ & 5029 (16.3) & - & - \\
\hline $76-90$ years & $10109(84.0)$ & $1930(16.0)$ & $1.02(0.97-1.08, p=0.461)$ & $1.20(1.11-1.29, p<0.001)$ \\
\hline$>90$ years $\dagger \dagger$ & $460(74.4)$ & $158(25.6)$ & $0.57(0.47-0.68, p<0.001)$ & $0.92(0.73-1.17, p=0.487)$ \\
\hline Per decade (Mean (SD)) & $6.0(1.4)$ & $5.8(1.6)$ & $1.14(1.13-1.15, p<0.001)$ & $1.17(1.15-1.19, p<0.001)$ \\
\hline \multicolumn{5}{|l|}{ Gender } \\
\hline Male (Reference) & 37569 (83.3) & $7558(16.7)$ & - & - \\
\hline Mixed & $845(77.7)$ & $242(22.3)$ & $0.77(0.67-0.90, p=0.001)$ & $0.90(0.75-1.09, p=0.264)$ \\
\hline Black & $11869(82.9)$ & $2454(17.1)$ & $1.07(1.01-1.13, p=0.014)$ & $1.02(0.95-1.09, p=0.590)$ \\
\hline South Asian & $29708(85.4)$ & $5084(14.6)$ & $1.29(1.24-1.35, p<0.001)$ & $1.16(1.09-1.23, p<0.001)$ \\
\hline Chinese & $536(89.8)$ & $61(10.2)$ & $1.94(1.50-2.56, p<0.001)$ & $1.91(1.39-2.71, p<0.001)$ \\
\hline Any other Asian background & $4683(88.0)$ & $640(12.0)$ & $1.62(1.48-1.77, p<0.001)$ & $1.30(1.17-1.45, p<0.001)$ \\
\hline Any other ethnic group & $2248(83.0)$ & $460(17.0)$ & $1.08(0.97-1.20, p=0.145)$ & $1.05(0.92-1.20, p=0.453)$ \\
\hline Unknown†† & $476(41.6)$ & $668(58.4)$ & $0.16(0.14-0.18, p<0.001)$ & $0.32(0.27-0.38, p<0.001)$ \\
\hline \multicolumn{5}{|l|}{ IMD quintiles } \\
\hline $\begin{array}{l}\text { 1st (most deprived, } \\
\text { reference) }\end{array}$ & $20136(81.9)$ & $4456(18.1)$ & - & - \\
\hline Type 1DM & $2223(75.8)$ & $710(24.2)$ & $0.55(0.51-0.60, p<0.001)$ & $1.09(0.96-1.25, p=0.190)$ \\
\hline Type 2 DM (Reference) & $67265(85.0)$ & $11851(15.0)$ & - & - \\
\hline MODY & $40(81.6)$ & $9(18.4)$ & $0.78(0.40-1.72, p=0.508)$ & $0.85(0.40-2.07, p=0.687)$ \\
\hline Not specified/other†† & $877(37.3)$ & $1474(62.7)$ & $0.10(0.10-0.11, p<0.001)$ & $0.46(0.40-0.53, p<0.001)$ \\
\hline \multicolumn{5}{|l|}{ Duration of diabetes } \\
\hline 1-10years (Reference) & $44890(83.6)$ & $8778(16.4)$ & - & - \\
\hline $11-20$ years & $20327(86.3)$ & $3236(13.7)$ & $1.23(1.18-1.28, p<0.001)$ & $0.99(0.92-1.06, p=0.727)$ \\
\hline$>20$ years & $5057(83.8)$ & $977(16.2)$ & $1.01(0.94-1.09, p=0.743)$ & $0.87(0.78-0.97, p=0.011)$ \\
\hline Unknownt† & $131(11.1)$ & $1053(88.9)$ & $0.02(0.02-0.03, p<0.001)$ & $0.35(0.26-0.47, p<0.001)$ \\
\hline Per 5 years(Mean (SD)) & $1.9(1.5)$ & $1.7(1.5)$ & $1.05(1.04-1.07, p<0.001)$ & $0.97(0.95-1.00, p=0.019)$ \\
\hline \multicolumn{5}{|l|}{ Distance to centre } \\
\hline$\leq 1-2 \mathrm{~km}$ (Reference) & $55436(83.8)$ & $10752(16.2)$ & - & - \\
\hline $3-5 \mathrm{~km}$ & $12895(82.4)$ & $2758(17.6)$ & $0.91(0.87-0.95, p<0.001)$ & $0.97(0.91-1.03, p=0.301)$ \\
\hline $6-8 \mathrm{~km}$ & $1044(80.4)$ & $254(19.6)$ & $0.80(0.70-0.92, p=0.001)$ & $0.90(0.75-1.09, p=0.268)$ \\
\hline$\geq 9 \mathrm{~km}$ & $190(75.7)$ & $61(24.3)$ & $0.60(0.46-0.81, p=0.001)$ & $0.66(0.46-0.97, p=0.027)$ \\
\hline Unknown & $840(79.3)$ & $219(20.7)$ & $0.74(0.64-0.87, p<0.001)$ & $0.93(0.77-1.12, p=0.433)$ \\
\hline Per km(Mean (SD)) & $1.7(1.6)$ & $1.8(1.7)$ & $0.97(0.96-0.98, p<0.001)$ & $0.99(0.97-1.00, p=0.031)$ \\
\hline
\end{tabular}


Table 1 Continued

\begin{tabular}{|c|c|c|c|c|}
\hline Dependent: Attended* & Attended $n=70405(83.4 \%)$ & $\begin{array}{c}\text { Did not attend } n=14044 \\
(16.6 \%)\end{array}$ & $\begin{array}{l}\text { Univariable OR (95\% Cl, } \\
\text { p-value) }\end{array}$ & $\begin{array}{c}\text { Multivariable adjusted OR† } \\
(95 \% \mathrm{Cl}, \mathrm{p} \text {-value })\end{array}$ \\
\hline \multicolumn{5}{|l|}{ PTAL tertiles } \\
\hline 1st tertile & $23281(83.2)$ & $4714(16.8)$ & $0.95(0.90-1.01, p=0.083)$ & $0.95(0.89-1.02, p=0.189)$ \\
\hline 2nd tertile & $36535(83.4)$ & $7291(16.6)$ & $0.96(0.91-1.02, p=0.192)$ & $0.97(0.90-1.03, p=0.309)$ \\
\hline 3rd tertile (Reference) & $10589(83.9)$ & 2039 (16.1) & - & - \\
\hline \multicolumn{5}{|l|}{ Visual acuity } \\
\hline 6/6 to 6/9 (Reference) & $52035(89.4)$ & $6158(10.6)$ & - & - \\
\hline$<6 / 9$ to $6 / 18$ & $3459(84.7)$ & $626(15.3)$ & $0.65(0.60-0.72, p<0.001)$ & $0.60(0.55-0.66, p<0.001)$ \\
\hline Worse than $6 / 18 \dagger \dagger$ & $683(78.4)$ & $188(21.6)$ & $0.43(0.37-0.51, p<0.001)$ & $0.40(0.34-0.48, p<0.001)$ \\
\hline Per five letters(Mean (SD)) & $16.5(1.6)$ & $16.3(2.0)$ & $1.07(1.06-1.08, p<0.001)$ & $1.12(1.11-1.14, p<0.001)$ \\
\hline \multicolumn{5}{|l|}{ Years of registration } \\
\hline 16-20years & $406(89.6)$ & $47(10.4)$ & $2.05(1.53-2.81, p<0.001)$ & $1.94(1.35-2.89, p=0.001)$ \\
\hline Per year(Mean (SD)) & $6.9(3.9)$ & $6.3(3.9$ & $1.04(1.04-1.05, p<0.001)$ & $1.02(1.01-1.03, p<0.001)$ \\
\hline
\end{tabular}

Observations are for 84449 individuals.

Bold $\mathrm{p}$ values indicate statistically significant results

Independent variables with missing data categorised as "Unknown": type of diabetes (2.8\%), duration of diabetes (1.4\%), distance to screening centre (1.3\%), and ethnicity (1.4\%).

${ }^{*}$ ORs greater than one imply greater odds of attendance.

†ORs mutually adjusted for all factors shown in the table.

$\ddagger$ Variable groups with uptake below the national diabetic eye screening programme uptake goal of $\geq 75 \%$. Independent variables with missing data categorised as

"Unknown": type of diabetes (2.8\%), duration of diabetes (1.4\%), distance to screening centre (1.3\%), and ethnicity (1.4\%).

IMD, Index of Multiple Deprivation; MODY, Maturity onset diabetes of the young; PTAL, Public Transport Accessibility Level.

People with $>15$ years of registration showed almost twice the odds of attendance than people with $<5$ years of registration. The OR per 5 years of registration was $1.02(95 \%$ CI 1.01 to 1.03 , p value $<0.001)$.

\section{DISCUSSION}

We found that people of Mixed or Black ethnicity with diabetes show very similar likelihoods of attendance at diabetic eye screening appointments compared with White British individuals. People of all asian ethnicities were more likely to attend than White British people in this large, well organised, sociodemographically diverse urban DESP. This is the most current study with large scale data on ethnicity and diabetic eye screening. In addition, those with poorer visual acuity, younger age and residing in areas with higher levels of deprivation were less likely to attend for diabetic eye screening appointments.

\section{Principal findings and comparison with other studies}

Black, Asian and minority ethnic (BAME) groups have been reported to be more likely to develop diabetic retinopathy than White Europeans, more likely to present with sight-threatening retinopathy, ${ }^{15} 3738$ and less likely to attend for diabetic eye screening. ${ }^{14} 1523$ Attendance rates for BAME groups in our study were all higher than the White British, except for the small Mixed ethnic group, which had a lower, though non-significant, rate of attendance (4.2\% uptake difference). Chinese, South Asian and any other Asian background ethnicities were most likely to attend, more so than any other ethnic group. These findings suggest that the underlying increased rates of retinopathy and sight-threatening retinopathy reported in BAME ethnic groups ${ }^{38} 39$ are not explained by non-attendance, raising the issue of increased susceptibility or poorer diabetic control. A study by Gulliford et al. ${ }^{15}$ analysing sociodemographic inequalities in diabetic eye screening in South London also reported that African, Caribbean and other ethnicity groups were more likely to attend for diabetic eye screening than White Europeans. Of note is that there was a higher proportion of missing ethnicity data in their study when compared to ours ( $39 \%$ vs $1.4 \%$, respectively).

The commissioning and provision of diabetes eye screening programmes in England has improved since previous analyses were conducted, this may explain some of the difference between this and previous studies. The cultural and language barriers perceived to prevent older people from BAME groups attending in previous studies have proven to be misplaced. All appointment letters are written in English, these data show that the language of the letter was no barrier to better attendance. Indeed, uptake was higher among older people and those from BAME groups. 
Socioeconomic deprivation has consistently been associated with attendance, where those from more deprived areas are less likely to attend for eye screening appointments. ${ }^{141619202526}$ Although the overall average difference in attendance of $3.5 \%$ between most and least deprived areas found in our study is less than the $9.3 \%$ reported in earlier studies, ${ }^{25}$ this is still greater than the $2 \%$ uptake difference found in a population from South London in 2010. ${ }^{15}$ Our results provide further evidence of the ingrained health inequalities present in a multiethnic study population with high levels of deprivation. Also, we show the effect of multiple risk factors that appear to impact on attendance. Longer duration of diabetes and worsening visual acuity showed an association with non-attendance compared with individuals with shorter disease duration and better visual acuity. Previous reports have shown an association of longer duration of diabetes with non-attendance ${ }^{1516}$ Given that duration of diabetes is one of the three major risk factors for diabetic retinopathy, ${ }^{4041}$ and considering that $>60 \%$ of people with type 2 diabetes and almost all people with type 1 diabetes will have diabetic retinopathy after $20+$ years duration of the disease ${ }^{40}$ the reduced odds of attendance observed in this group places them at increased risk of visual complications. There is, to our knowledge, no evidence available about the association of visual acuity with attendance to diabetic eye screening.

In other areas of the UK, increased distance from screening clinic has been associated with an increased risk of non-attendance. ${ }^{19} 37$ We have found that only individuals living $\geq 9 \mathrm{~km}$ from a screening centre were less likely to attend. It is noteworthy that an $8 \mathrm{~km}$ radius from one of the NELDESP screening centre covers all of the geographical areas of these six CCGs. People who are living more than $8 \mathrm{~km}$ from a screening centre have moved outside the CCG area and but remain registered with a North East London GP . Interestingly, we found that the association of distance to screening centre with non-attendance is independent from PTALs in this innercity population. This may be due to London having a well-developed public transport network and good transport-related access. These findings may not apply elsewhere, particularly to non-urban populations less served by public transport.

In accordance with previous evidence, ${ }^{10} 14-1619204243$ young individuals from 12 to 45 years of age had lower odds of attendance compared with people aged 46-60 years. Possible underpinning factors are over confidence about their health or demanding work schedules. ${ }^{19} 24$ Nonetheless, within the context of diabetes chronicity and the need for regular contact with healthcare services, these individuals are at increased risk of complications through longer duration of disease and possible suboptimal metabolic control. ${ }^{44}$

Our study has several strengths. First, a large sample size with considerable proportions of individuals from different ethnic groups representing a diverse population group all living within the programme area, with one of the most complete data sets on ethnicity reported to date. Second, the use of PTALs in addition to distance to screening centre to evidence the associations of accessibility and transport with attendance. And third, the fact that three-quarters of the participants were distributed between two of the most deprived quintiles of IMD, allowing the comparative association between deprivation and ethnicity with attendance to be examined. Our study has several limitations. First, major systemic risk factors for diabetic retinopathy incidence and progression, namely hypertension and glycaemic control, were not available to include in our analysis. Second, we did not analyse the association of the sociodemographic variables with the presence of diabetic retinopathy, which although desirable, would have been difficult to ascertain for repeated non-attenders.

Further work to unravel the interplay between ethnicity, deprivation and disease severity, is needed to inform strategies to improve attendance, particularly in high risk under privileged groups.

\section{CONCLUSION}

Smaller previous studies have reported an association between non-White ethnicities and poor attendance at diabetic eye screening appointments. However, in this large diverse urban population, South Asian, Chinese and individuals of Any other Asian background were more likely to attend for diabetic eye screening than White British people. Public health strategies have in the past focused on ethnic differences as a possible cause of variance in diabetic eye screening uptake. The data from this large cohort shows that there are other more influential factors. We have shown that worse visual acuity, higher levels of deprivation, younger age and longer duration of diabetes are more predictive of nonattendance. Hence, strategies to improve uptake should be directed at these groups, in order to reduce inequalities in diabetic eye screening.

Twitter Abraham Olvera-Barrios @abraham_olvera1 and Adnan Tufail @adnan_ tufail1

Contributors All authors meet the ICMJE criteria for authorship. JA, CE, LB, AT, ARR, CG0 and AO-B: designed the study. A0-B, MS, TFCH and RC: undertook data management, processing and analysis. ARR, CGO and CE provided statistical advice and analysed the data. JA, CE, LB, ARR and AO-B wrote the first draft of the report, which was critically appraised by all authors. All the authors read and approved the final draft for journal publication. JA is responsible for data integrity.

Funding This research has received a proportion of its funding from the Department of Health's NIHR Biomedical Research Centre for Ophthalmology at Moorfields Eye Hospital and UCL Institute of Ophthalmology (salary support for A.T. and C.E.), and from the Mexican National Council of Science and Technology (CONACYT, scholarship \#2018-000009-01EXTF-00573 to A0-B).

Disclaimer The views expressed in the publication are those of the authors and not necessarily those of the Department of Health.

\section{Competing interests None declared.}

Patient and public involvement Patients and/or the public were involved in the design, or conduct, or reporting, or dissemination plans of this research. Refer to the Methods section for further details.

Patient consent for publication Not required. 
Ethics approval This study was registered as an audit and approved through the research governance process at the Homerton University Hospital NHS Foundation Trust and adhered to the UK Data Protection Act 2018.

Provenance and peer review Not commissioned; externally peer reviewed.

Data availability statement Data are available upon reasonable request. The data that supports the findings of this study are available from the North East London Diabetic Eye Screening Programme upon reasonable request.

Open access This is an open access article distributed in accordance with the Creative Commons Attribution 4.0 Unported (CC BY 4.0) license, which permits others to copy, redistribute, remix, transform and build upon this work for any purpose, provided the original work is properly cited, a link to the licence is given, and indication of whether changes were made. See: https://creativecommons.org/ licenses/by/4.0/.

\section{ORCID iDs}

Abraham Olvera-Barrios http://orcid.org/0000-0002-3305-4465

Tjebo F C Heeren http://orcid.org/0000-0001-5297-2301

Ryan Chambers http://orcid.org/0000-0001-5322-4209

Louis Bolter http://orcid.org/0000-0002-8710-8916

Adnan Tufail http://orcid.org/0000-0001-6131-7640

Christopher G Owen http://orcid.org/0000-0003-1135-5977

Alicja R Rudnicka http://orcid.org/0000-0003-0369-8574

Catherine Egan http://orcid.org/0000-0002-4439-3489

John Anderson http://orcid.org/0000-0002-2355-9742

\section{REFERENCES}

1 Liew G, Michaelides M, Bunce C. A comparison of the causes of blindness certifications in England and Wales in working age adults (16-64 years), 1999-2000 with 2009-2010. BMJ Open 2014;4:e004015.

2 Solomon SD, Chew E, Duh EJ, et al. Diabetic retinopathy: a position statement by the American diabetes association. Diabetes Care 2017;40:412-8.

3 Diabetes UK. Diabetes prevalence, 2019. Available: https://www. diabetes.org.uk/professionals/position-statements-reports/statistics/ diabetes-prevalence-2019 [Accessed 27 Feb 2020].

4 Mathur R, Bhaskaran K, Edwards E, et al. Population trends in the 10-year incidence and prevalence of diabetic retinopathy in the UK: a cohort study in the clinical practice research Datalink 2004-2014. BMJ Open 2017;7:e014444

5 Scanlon $\mathrm{PH}$. The English national screening programme for diabetic retinopathy 2003-2016. Acta Diabetol 2017;54:515-25.

6 Wong TY, Sun J, Kawasaki R, et al. Guidelines on diabetic eye care: the International Council of ophthalmology recommendations for screening, follow-up, referral, and treatment based on resource settings. Ophthalmology 2018;125:1608-22.

7 Virk R, Binns AM, Chambers R, et al. How is the risk of being diagnosed with referable diabetic retinopathy affected by failure to attend diabetes eye screening appointments? Eye 2021;35:477-83

8 Public Health England. Diabetic eye screening standards valid for data collected from 1 April 2019, 2019. Available: https:// www.gov.uk/government/publications/diabetic-eye-screeningprogramme-standards/diabetic-eye-screening-standards-valid-fordata-collected-from-1-april-2019\#des-s07-uptake-routine-digitalscreening [Accessed 27 Feb 2020].

9 Public Health England. Diabetic eye screening: 2016 to 2017 data, 2017. Available: https://www.gov.uk/government/publications/ diabetic-eye-screening-2016-to-2017-data [Accessed 01 Jul 2020]

10 Forster AS, Forbes A, Dodhia H, et al. Non-attendance at diabetic eye screening and risk of sight-threatening diabetic retinopathy: a population-based cohort study. Diabetologia 2013;56:2187-93.

11 Borrell C, Pons-Vigués M, Morrison J, et al. Factors and processes influencing health inequalities in urban areas. J Epidemiol Community Health 2013;67:389-91.

12 Riva M, Curtis S, Gauvin L, et al. Unravelling the extent of inequalities in health across urban and rural areas: evidence from a national sample in England. Soc Sci Med 2009;68:654-63.

13 Dorling D. Editorial-Inequality and injustice: some news from Britain. Urban Geogr 2012;33:621-9.

14 Millett $\mathrm{C}$, Dodhia $\mathrm{H}$. Diabetes retinopathy screening: audit of equity in participation and selected outcomes in South East London. J Med Screen 2006;13:152-5.

15 Gulliford MC, Dodhia H, Chamley M, et al. Socio-economic and ethnic inequalities in diabetes retinal screening. Diabet Med 2010;27:282-8.
16 Leese GP, Boyle P, Feng Z, et al. Screening uptake in a wellestablished diabetic retinopathy screening program: the role of geographical access and deprivation. Diabetes Care 2008;31:2131-5.

17 Dervan E, Lillis D, Flynn L, et al. Factors that influence the patient uptake of diabetic retinopathy screening. Ir J Med Sc 2008;177:303-8.

18 van Eijk KND, Blom JW, Gussekloo J, et al. Diabetic retinopathy screening in patients with diabetes mellitus in primary care: incentives and barriers to screening attendance. Diabetes Res Clin Pract 2012;96:10-16.

19 Moreton RBR, Stratton IM, Chave SJ, et al. Factors determining uptake of diabetic retinopathy screening in Oxfordshire. Diabet Med 2017;34:993-9.

20 Orton E, Forbes-Haley A, Tunbridge L, et al. Equity of uptake of a diabetic retinopathy screening programme in a geographically and socio-economically diverse population. Public Health 2013;127:814-21.

21 Gange WS, Xu BY, Lung K, et al. Rates of eye care and diabetic eye disease among insured patients with newly diagnosed type 2 diabetes. Ophthalmol Retina 2021;5:160-168.

22 Al-Alawi A, Al-Hassan A, Chauhan D, et al. Knowledge, attitude, and perception of barriers for eye care among diabetic persons registered at employee health department of a tertiary eye Hospital of central Saudi Arabia. Middle East Afr J Ophthalmol 2016;23:71-4

23 Fathy C, Patel S, Sternberg P, et al. Disparities in adherence to screening guidelines for diabetic retinopathy in the United States: a comprehensive review and guide for future directions. Semin Ophthalmol 2016;31:364-77.

24 Lindenmeyer A, Sturt JA, Hipwell A, et al. Influence of primary care practices on patients' uptake of diabetic retinopathy screening: a qualitative case study. Br J Gen Pract 2014;64:e484-92.

25 Scanlon $\mathrm{PH}$, Carter SC, Foy C, et al. Diabetic retinopathy and socioeconomic deprivation in Gloucestershire. J Med Screen 2008;15:118-21.

26 Waqar S, Bullen G, Chant S, et al. Cost implications, deprivation and geodemographic segmentation analysis of non-attenders (DNA) in an established diabetic retinopathy screening programme. Diabetes Metab Syndr 2012;6:199-202.

27 Public Health England. Screening quality assurance visit report. NHS diabetic eye screening service North East London diabetic eye screening programme, 2017.

28 Ministry of Housing Communities \& Local Government. The English indices of deprivation, 2019.

29 Pittini M, Rocks C, Leeser R. London geographies and economic performance - insights from the local industrial strategy evidence base interim report. . GLA Economics, 2019: 215. 12-16.

30 Office of National Statistics. Ethnicity and national identity in England and Wales, 2011. Available: https://www.ons.gov.uk/peoplepopula tionandcommunity/culturalidentity/ethnicity/articles/ethnicityandnati onalidentityinenglandandwales/2012-12-11\#measuring-ethnicity [Accessed 13 Apr 2020].

31 Government UK. Uk population by ethnicity. regional ethnic diversity, 2011. Available: https://www.ethnicity-facts-figures.service.gov. uk/uk-population-by-ethnicity/national-and-regional-populations/ regional-ethnic-diversity/latest [Accessed 5 Jul 2020].

32 Public Health England. Diabetic eye screening: cohort management. Available: https://www.gov.uk/government/publications/diabetic-eyescreening-cohort-management-overview/diabetic-eye-screeningcohort-management [Accessed 01 July 2020].

33 Olvera-Barrios A, Heeren TF, Balaskas K, et al. Comparison of truecolour wide-field confocal scanner imaging with standard fundus photography for diabetic retinopathy screening. $\mathrm{Br} J$ Ophthalmol 2020;104:bjophthalmol-2019-315269.

34 Transport for London. Public transport accessibility levels, 2017. Available: https://data.london.gov.uk/dataset/public-transportaccessibility-levels\#: :text=The\%20method\%20is\%20essentially\% 20 a,excellent $\% 20$ access $\% 20$ to\%20public\%20transport [Accessed 6 Jul 2020].

35 Transport for London. WebCAT planning tool, 2017. Available: https://tfl.gov.uk/info-for/urban-planning-and-construction/planningwith-webcat/webcat?intcmp=25932 [Accessed 6 Jul 2020].

36 R Core Team. R: A Language and Environment for Statistical Computing [program. Viena, Austria: R Foundation for Statistical Computing, 2020.

37 Kliner M, Fell G, Gibbons C, et al. Diabetic retinopathy equity profile in a multi-ethnic, deprived population in northern England. Eye 2012;26:671-7

38 Sivaprasad S, Gupta B, Gulliford MC, et al. Ethnic variation in the prevalence of visual impairment in people attending diabetic 
retinopathy screening in the United Kingdom (drive UK). PLoS One 2012;7:e39608.

39 Sivaprasad S, Gupta B, Crosby-Nwaobi R, et al. Prevalence of diabetic retinopathy in various ethnic groups: a worldwide perspective. Surv Ophthalmol 2012;57:347-70.

40 Fong DS, Aiello L, Gardner TW, et al. Retinopathy in diabetes. Diabetes Care 2004;27:S84-7.

41 Yau JWY, Rogers SL, Kawasaki R, et al. Global prevalence and major risk factors of diabetic retinopathy. Diabetes Care 2012;35:556-64.
42 Scanlon PH, Stratton IM, Leese GP, et al. Screening attendance, age group and diabetic retinopathy level at first screen. Diabet Med 2016;33:904-11.

43 Ahmad B, Neilson F. A health equity audit of the diabetic eye screening programmes in Cumbria and the North East. Br J Diabetes 2019;19:42-4.

44 Hainsworth DP, Bebu I, Aiello LP, et al. Risk factors for retinopathy in type 1 diabetes: the DCCT/EDIC study. Diabetes Care 2019;42:875-82. 